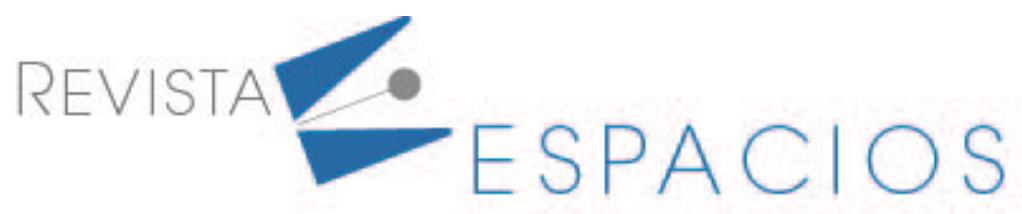

Vol. 42 (09) $2021 \cdot$ Art. 3

Recibido/Received: 27/01/2021 • Aprobado/Approved: 07/05/2021 • Publicado/Published: 15/05/2021

\title{
Economia compartilhada no segmento de turismo
}

\section{Shared economy in the tourism segment}

\author{
FREITAS-PEREIRA, Marcos ${ }^{1}$ \\ RAMÍREZ-SÁNCHEZ, Miguel Y. ${ }^{2}$ \\ FLORENCIO DA SILVA, Rodrigo ${ }^{3 *}$
}

\begin{abstract}
Resumo
O objetivo do artigo é aplicar os conceitos da economia compartilhada no segmento de turismo na cidade de Olímpia, conhecido como multipropriedade, no sentido de aumentar o número de visitantes no destino turístico. A implantação do modelo de multipropriedade aumentará a oferta de unidades hoteleiras e como isso gerará mais visitas à cidade alavancando os resultados do turismo. Pelos resultados apresentados nesse artigo, o modelo poderá ser adotado em outras regiões turísticas do Brasil e do mundo.

Palavras-chave: economia compartilhada, turismo, imobiliário e multipropriedade.
\end{abstract}

\begin{abstract}
The abstrat of the article is to apply the concepts of sharing economy in the tourism segment in the city of Olympia, known as multi-property, in order to increase the number of visitors to the tourist destination. The implementation of the model will increase the offer of hotel units and how it will bring more customers to the city leveraging tourism results. From the results presented, the model can be applied in others tourists regions of Brazil and the world.

Keywords: sharing economy, tourism, real estate and multi-property.
\end{abstract}

\section{Introdução}

O ano de 2020 foi um ano atípico para o mundo. O surgimento da pandemia COVID-19 deixou todos paralisados, sem nenhuma ação. No Brasil especificamente a pandemia iniciou-se em fevereiro de 2020, teve o seu pico em agosto e em dezembro uma segunda onda tomou conta do mundo e também do Brasil. Como esse artigo tratase de turismo não se pode deixar de mencionar a pandemia, pois foi o setor que mais sofreu na economia mundial em função das políticas de isolamento social adotadas por todos os países. No Brasil o turismo ficou paralisado aproximadamente 7 meses. Os resultados obtidos na pesquisa do presente artigo, em função da pandemia, ficaram delimitados em 3 meses, porém, eles foram satisfatórios demonstrando uma tendência à resposta do objeto da mesma.

\footnotetext{
${ }^{1}$ Estudante de doutorando. Universidad Internacional Iberoamericana - UNINI e WAM Brasil. marcos.freitas@wambrasil.com

2 Professor pesquisador. Universidade Internacional do Cuanza (Angola) e Universidad Internacional Iberoamericana (México). Email: miguel.ramirez@unic.co.ao

${ }^{3}$ Professor-Pesquisador. Secretaría de Investigación y Posgrado. Instituto Politécnico Nacional - IPN e colaborador na Universidade Internacional do Cuanza - UNIC.rflorencio@ipn.mx*
} 
As atividades do turismo no Brasil retornaram-se nos meses de setembro e outubro, a cidade de Olímpia, objeto de estudo do artigo, retomou as suas atividades em setembro, após praticamente 6 meses fechada sem receber turistas. A volta da atividade turística obedeceu critérios rigorosos de procedimentos, entre os quais destacaramse: 1) redução da capacidade de atendimento nos hotéis e nos parques de 50\%; 2) distanciamento das mesas de restaurantes, salas de vendas em 2 metros; 3) redução de pessoas em uma mesma mesa; 4) uso intensivo de álcool em gel, na entrada, na permanência e na saída dos ambientes; 5) comunicação intensiva para os clientes; 6) uso obrigatório de máscara e 7) desinfeçção dos ambientes após o uso pelo cliente.

Não obstante ao cenário de pandemia contextualizada acima, não se tem mais dúvidas no Brasil da importância do setor de turismo para a economia. Ele é um setor propulsor de renda e de emprego, além, de ter uma cadeia de negócios extensa ao seu redor (Petrochi, 2001). Segundo o autor, o turismo é o setor mais dinâmico do século XXI.

O turismo é um dos setores mais empregadores de mão de obra na economia de um país. Alguns apresentam no turismo um dos seus principais geradores de renda, entre eles são exemplos: os Estados Unidos, Espanha, México e mais recentemente Portugal.

Nos últimos anos, o desemprego no Brasil deu sinais de crescimento, já são $14 \%$ da mão de obra sem emprego, uma cifra de 14 milhões de pessoas em função da situação econômica do país, enquanto isso o setor de turismo, cresceu neste período em dois dígitos, ou seja, o turismo ficou na contramão da crise, exceto no período da pandemia.

Este seria o momento ideal dos governantes do Brasil pensarem no turismo como forma de geração de renda e de emprego para o país. O segmento de turismo no Brasil não tem sido pensado estrategicamente pelos seus governantes. O turismo no Brasil é eminentemente interno, o seu potencial é muito grande, já são mais de 208 milhões de habitantes, um mercado consumidor muito atrativo. Além deste mercado consumidor, o Brasil possui muitos encantos naturais, longa extensão de praias tropicais, destinos de serras, destinos ecológicos, ou seja, um cardápio vasto de opções de regiões turísticas. Trata-se de uma indústria recente e que demanda maior profissionalização (Lage e Milone, 2000).

O grande desafio da economia brasileira é conseguir ultrapassar a barreira da renda média para a renda alta, premissa básica para ser um país desenvolvido (Pereira, Veloso e Bingwen, 2013) e o setor de turismo pode contribuir para isso.

Dentre os produtos de turismo que surgiram nos últimos tempos, produtos e serviços de utilização compartilhada destacaram-se. Em princípio, na oferta hoteleira, comercializando o time sharing (tempo compartilhado) com direito de uso por um determinado período de tempo e, recentemente, na oferta imobiliária turística através da comercialização de contratos de multipropriedade, onde a venda é de uma propriedade real, ou seja, direito real e não mais direito de uso.

O artigo inicia-se com o estudo da evolução do capitalismo demonstrando o que muitos autores pesquisaram sobre o assunto, a sua instabilidade e suas frequentes crises. Logo em seguida o assunto a ser tratado será da economia compartilhada, o estado de arte desta nova ciência. Demonstrados estes macros eixos teóricos do artigo, tratará, na sequência, a segmentação do mesmo, iniciando-se com o estudo do mercado de turismo global e do Brasil, seus fundamentos, seus pré-requisitos, sua importância na economia de um país. Derivados do estudo do mercado de turismo, serão estudadas as ramificações do turismo, estudo da hotelaria em destinos turísticos, o modelo de incorporação imobiliária de condo-hotéis e finalizando com o mercado da multipropriedade imobiliária turística e sua contribuição para alavancar os negócios de turismo. 


\section{Metodologia}

A metodologia utilizada no artigo baseou-se na revisão bibliográfica da economia compartilhada nos diversos setores econômicos. Para apuração dos resultados foi adotada a pesquisa quantitativa correlacional. A variável dependente é o aumento da oferta de unidades habitacionais através do modelo de multipropriedade na cidade de Olímpia e as variáveis independentes são: o crescimento do número de clientes hospedados no hotel Olímpia Parque Resorts; o crescimento do número consolidado de clientes nos dois parques aquáticos, Thermas dos Laranjais e Hot Beach e o crescimento da receita de impostos obtidos pela cidade de Olímpia, comparando período do ano com o mesmo período do ano anterior em função da sazonalidade do turismo e excluindo o período afetado pela pandemia do Covid-19.

\subsection{Referencial Teórico}

A economia compartilhada, novo momento do capitalismo mundial, que transcende a simples compra e venda de bens e serviços. Nesta nova economia o determinante é o acesso e não a posse, bens e serviços são compartilhados livremente entre as pessoas.

Pode-se entender que a economia compartilhada nada mais é do que uma derivação do capitalismo, mais profundamente, uma resposta às crises frequentes que o sistema tem sofrido nos últimos anos.

Alguns autores escreveram, estudaram e pesquisaram sobre a dinâmica da economia capitalista, e muitos deles, apontam para estas crises como forma crítica do sistema econômico. O sistema capitalista é sem dúvida a melhor forma de sistema que a economia já produziu, porém, sofre de instabilidade gerada internamente pelo próprio sistema. E em alguns momentos, como respostas a estas crises, surgem alternativas de reparos e "salvação" do sistema. É neste contexto que se insere a economia compartilhada.

\subsubsection{Capitalismo}

Segundo Piketty (2014), a história do capitalismo sempre foi marcada por previsões pessimistas em função desta instabilidade que acompanha o sistema desde a sua origem. O primeiro historiador econômico a fazer previsões catastróficas foi Malthus, ele previa uma superpopulação e que haveria escassez de alimentos para a quantidade de pessoas que crescia em base de progressão geométrica. Outro economista que fez previsões pessimistas foi David Ricardo, por sua vez, a escassez de terra levaria os preços da mesma subirem de forma significativa. E por último, ainda segundo Piketty (2014), as economias que previa o fim do capitalismo como inevitável, Karl Marx. Marx fez um estudo brilhante de como era a dinâmica do sistema e previu que o capitalismo seria extinto em função da apropriação, sem a remuneração adequada, da força de trabalho pelo capital, ou seja, pelos capitalistas.

Picketty (2014), em sua obra O capital no século XXI, preocupou-se em analisar o capitalismo na sua forma de distribuição de renda, ou melhor, na desigualdade de renda que o sistema propicia e talvez resida o maior desafio do capitalismo como sistema. Ele deve prover de igual maneira tanto a remuneração do capital para os capitalistas, bem como, prover a remuneração da força de trabalho pelos trabalhadores.

Já para Kother (2015), o capitalismo tem gerado, na sua história, ciclos econômicos, ele cita que de 1857 até a 2019 a economia norte americana passou por 33 recessões, o que demonstra claramente a instabilidade do sistema capitalista. Para ele os ciclos econômicos passam por 4 fases distintas: contração; mínimo, expansão e máximo. A política econômica de qualquer país tem como objetivo principal o crescimento sustentável.

Em função dessas crises que surge a economia compartilhada como resposta a elas e como alternativa de salvar o capitalismo. 


\subsubsection{Economia Compartilhada}

Esta nova economia, ou nova indústria, denominada de economia ou indústria do compartilhamento é vista por alguns estudiosos como sendo a descoberta mais importante depois do capitalismo e do socialismo, trata-se de uma nova fase do capitalismo. O importante nesta economia é o uso dos recursos já existentes: ativos físicos, dados, redes, destrezas, dispositivos, conhecimentos prévios e procedimentos, há uma mudança de visão do privado para o público, do uso comercial para o uso pessoal (Chase, 2015).

A antiga economia estava alicerçada na ideia de acumulação de bens, ter o seu próprio carro, a sua casa de praia e os seus discos compactos, eram sinônimos de prosperidade. Com isso acumulou-se, com o decorrer do tempo, um enorme ativo ocioso e as vezes perdido. A literatura econômica mundial tem dedicado grande tempo em pesquisar e escrever sobre os avanços desta nova economia, que no seu cenário futuro prevê uma nova forma de fazer negócios. Exemplos disso são os estudos das novas organizações empresariais que estão se formando nesta nova economia (Botsman e Rogers, 2011).

A questão teórica desta nova economia está fundamentada em três grandes teses Chase (2015), fundadora da empresa de serviços de automóveis compartilhado, a Zipcar, descreve estas como sendo: a primeira tese é do aspecto financeiro, pois, as pessoas compartilhando bens e não comprando, a conta financeira fecha, o uso passa a ser mais importante do que o ter, eu não quero ter carro eu quero usá-lo. Definitivamente é o momento das pessoas pagarem por aquilo que usa e não por aquilo que tem. Mais pessoas poderão adquirir o bem ou o serviço.

A segunda tese refere-se a plataforma física ou digital que vai facilitar o compartilhamento. $O$ uso da tecnologia é importante nesta nova etapa da economia mundial. O uso do carro através da plataforma UBER deve ser facilitado pela sua tecnologia, além, do relacionamento entre o motorista e o cliente. A compra de livros na Amazon e as indicações de livros da sua preferência são facilidades permitidas pela tecnologia. $O$ aluguel de um apartamento pelo sistema AIRBNB deve ser facilitado também pela tecnologia. Tanto a solicitação do serviço, bem como, pelo pagamento pelos serviços e ainda o relacionamento com esta nova economia deverão ser os diferenciais.

A terceira e última tese é a relação de confiança que deve existir entre o demandador do serviço ou do produto e o ofertador deste serviço ou do produto. Esta relação que vai dar solidez as negociações realizadas nesta nova economia. Deve haver confiança mútua entre as duas partes.

Por outro lado, a economia compartilhada tem ensejado um melhor aproveitamento dos ativos do planeta, em um uso mais racional, objetivando a redução do impacto no meio ambiente. Por que utilizar um carro por cada membro da família contribuindo com a poluição do planeta se agora podemos usar os serviços do UBER? Por que os mais ricos precisam ter cada um uma aeronave onde o maior tempo desta fica ociosa, por que não compartilhar como outros interessados? Nesta nova economia surgem cada vez mais novas ideias. A nova geração pensa diferente das gerações anteriores, antes o ter era o mais importante, hoje o usar é mais importante. O acesso é a nova forma da economia do mundo (Rifkin, 2016 e Stone, 2017).

As redes sociais, explosão dos últimos anos, são a forma mais contundente desta nova economia, as pessoas estão conectadas por um clique, relacionam-se facilmente e podem compartilhar sentimentos, opiniões, bens, serviços, de forma instantânea (Castells, 2016).

A multipropriedade, tema deste artigo, origina-se na Europa compartilhando imóveis de valores elevados, com o objetivo de compartilhar os valores de investimentos, os valores de manutenção, condomínio, taxas de propriedade e equipamentos do imóvel entre os investidores de cada unidade imobiliária. Portanto uma unidade imobiliária de alto valor era compartilhada com diversos compradores. O compartilhamento destes imóveis eliminava a ociosidade destes ativos, pois, várias pessoas passaram a poder utilizá-los (Lima, 2017). 
No Brasil a multipropriedade também chegou para compartilhar imóveis de valores elevados, os primeiros negócios datam da 1a. década dos anos 2000, foram projetos de condomínios com quantidade de unidades imobiliárias bem restrita, entre 20 a 40 imóveis. No final desta mesma década a multipropriedade no Brasil passa a ser em condomínios com quantidade de unidades elevadas com preços bem menores, os projetos foram aumentando com o tempo de 100, para 300, para 500 e até 1000 imóveis em um único empreendimento. Aindo segundo Lima (2017), a diferença dos projetos do final da década para os projetos do início da década são os clientes e o eu poder aquisitivo, com isso o campo de cliente potencial comprador aumenta de maneira significativa, este produto passa a objetivar a classe média brasileira que corresponde a mais de $50 \%$ da população.

Portanto, a multipropriedade, tema deste artigo, está inserida neste novo momento da economia mundial, que é a economia do compartilhamento. $O$ uso passa a ser mais importante do que o ter, a propriedade individual dá lugar a posse temporária, os investimentos e os custos passam a serem divididos e minimizados. A "sacada" agora é pagar pelo que usa, não mais, pagar pelo o que você tem.

Segundo o sociólogo Renato Meireles, do Datapopular, "nada mais inteligente do que pagarmos apenas pelo que usamos" (Meireles, 2014).

Gansky (2011) criou o termo "mesh" para denominar esta nova economia. Segunda a autora trata-se do surgimento de um novo capitalismo do século XXI. Através do relacionamento humano e da cooperação formamse um novo paradigma de criação de riqueza. Segundo ela, "a mesh é o começo de um novo regime de propriedade intelectual e de bens físicos, tangíveis, condicionado pela inteligência coletiva que as redes móveis, ubíquas e participativas propiciam" (Gansky, 2011, p. 17).

Outros estudos, de outros autores, analisaram a economia colaborativa ou a economia de compartilhamento acrescentando outras observações e pesquisas importantes. O autor Riftkin (2001) cria a era do acesso como o nascimento desta nova economia. Dentro do contexto que foi discutido acima, o autor parte do pressuposto que o papel da propriedade está mudando radicalmente. Como a economia capitalista está fundada no alicerce da troca de bens materiais, na propriedade, na nova economia a propriedade está sendo substituída pelo acesso, não que com isso a propriedade deixará de existir. O que vai acontecer na nova economia é a redução dos negócios baseados na propriedade para o crescimento dos negócios baseados no acesso, porém, a propriedade deve existir para se ter o acesso. $O$ autor exemplifica empresas que vendem seus imóveis, se livrando do ativo, para logo em seguida, alugá-lo, onde terá o acesso ao imóvel.

Como preconizou Chase (2015), uma das teses defendidas por ela é a necessidade da existência de uma plataforma de venda para facilitar a economia compartilhada. Os autores Parker, Alstyne e Choudary (2016) defendem uma revolução na estratégia empresarial, a revolução da plataforma. Tem como objetivo facilitar o contato entre os usuários e facilitar a troca de bens, serviços ou moedas sociais, criando valor para todos os participantes. As empresas que adotaram a estratégia da plataforma tiveram crescimentos superiores às empresas tradicionais. Os autores citam os exemplos da UBER, AIRBNB, Google, Amazon, Microsoft e Ebay como empresas que adotaram a estratégia da plataforma.

Como dito anteriormente e segundo Rifkin (2016) sobre a economia de compartilhamento: "esse é o primeiro novo sistema econômico a entrar no palco mundial deste o advento do capitalismo e socialismo no início do século XIX, e ele continua: " a economia de compartilhamento já está mudando o modo como organizamos nossa vida econômica, oferecendo a possibilidade de reduzir drasticamente a divisão de renda, democratizar a economia global e criar uma sociedade mais ecologicamente sustentável" (Rifkin, 2016, p. 13).

Em sua obra Rifkin (2016), prevê uma mudança muito significativa na economia para os próximos anos, ela parte de um cenário já dado para depois prever as inovações que ocorreram e que estão ocorrendo. Ele cita como 
cenário atual a produtividade extrema que a economia alcançou com a utilização da tecnologia, a internet das coisas que facilita a transação de bens e serviços como muita facilidade, a energia gratuita, a impressão 3D que muda o paradigma de produção de massa para a produção pelas massas, cita ainda, a educação com custo marginal zero, "uma única sala de aula e bilhões de alunos".

Diante deste cenário o autor não tem dúvidas que muitas coisas mudarão, ascensão dos bens comuns colaborativos, um dos principais, a transformação de posse em acesso e o novo paradigma do trabalho, o trabalho do futuro não será como antes.

Esta economia compartilhada ou colaborativa terá um formato de um novo poder contra um velho, este novo poder que contribuirá para a ênfase desta nova economia. Este tema é discutido pelos autores Timms e Heimans (2018), o velho poder é caracterizado por ser de propriedade de poucos, é armazenado, fechado, inacessível e impulsionado por um dono, por um líder. Já o novo poder é como uma corrente, aberto, participativo, impulsionado por iguais, o objetivo do novo poder não é acumular e sim canalizar e distribuir.

\subsubsection{Setor de Turismo}

O turismo global movimentará 1,8 bilhões de pessoas em 2030, em 2017 já movimentou 1,3 bilhões, crescimento de $7 \%$ em relação ao ano anterior. O setor de turismo global representa 10,4\% do PIB e gera 7 vezes mais emprego do que a indústria automobilística, 5 vezes mais do que a indústria química e 3,5 vezes mais do que o setor bancário.

Se o setor do turismo é importante para o mundo, ele é mais importante ainda para o Brasil. Atualmente o Brasil tem 14 milhões de desempregados e investimentos no setor turístico pode captar uma boa parte destes desempregados no país a um custo de investimento bem menor do que a geração de empregos no setor industrial.

Além da questão econômica e social que os investimentos no setor de turismo podem resolver no Brasil, o país apresenta vários destinos turísticos, de praia, de serras, parques aquáticos e parques temáticos. Alguns destinos estão entre os mais badalados neste momento no Brasil: Fernando de Noronha (Pernambuco); Trancoso (Bahia); Búzios e Região dos Lagos (Rio de Janeiro) e Pipa (Rio Grande do Norte). Há uma previsão de crescimento de dois dígitos para o setor de turismo no Brasil para os próximos anos.

No governo iniciado em 2019 do Jair Bolsonaro, o ministro escolhido pelo Presidente foi o Marcelo Álvaro Antônio, na sua posse como ministro ele deixou bem claro que pretende colocar o turismo na pauta do país como vetor de geração de emprego, renda e desenvolvimento. Até hoje o Brasil não teve um governo que tenha focado suas ações no setor de turismo, até pouco tempo atrás não existia o Ministério do Turismo e tão pouco orçamento público para desenvolver o setor.

Segundo o Ministro do Turismo, nos próximos 4 anos, as ações do ministério gerarão 2 milhões de empregos, saindo de 7 milhões e atingindo 9 milhões. Estes 7 milhões de empregos gerados atualmente no setor de turismo corresponde a aproximadamente 6,5\% dos empregos no Brasil, muito abaixo dos 10\% em nível mundial.

Portanto, há necessidade eminente do país agir seriamente na questão do turismo, aproveitando as oportunidades do Brasil, belezas naturais, e resolvendo parte do grande problema econômico e social que é o desemprego.

Para Petrochi (2001) quando se fala em turismo é importante salientar que este setor é composto por vários componentes, tais como: atrações e atividades turísticas; alojamentos; outros serviços de turismo; elementos institucionais; outras infraestruturas e transportes $O$ local onde os produtos turísticos são ofertados e 
demandados são denominados de polos turísticos. No Brasil encontramos vários deles, em função da sua vasta região geográfica e das suas belezas naturais.

De acordo com o site Viagens Cinematográficas (2018), os dez destinos de turismo no Brasil mais procurado para viagem em 2019 são: Litoral Norte de Alagoas; Jericoacoara (Ceará); Porto de Galinha (Pernambuco); Fernando de Noronha; Búzios e Região dos Lagos; Gramado (RS), Chapada dos Veadeiros (GO); Morro de São Paulo (BA); Pipa (RN) e Lençóis Maranhense (MA).

Estes dez destinos são uma amostra de um potencial muito grande do turismo no Brasil. Há uma concorrência grande entre eles, e o seu principal cliente são os residentes do Estado de São Paulo, o maior emissor de turistas de todos os destinos turísticos importante no país.

A gestão do setor do turismo passa necessariamente pela gestão do destino turístico, ou como denomina Petrochi (2001), de gestão de polos turísticos. E no contexto desta gestão, além, de capacitar os profissionais que atendam os turistas, além de oferecerem produtos de qualidade e serviços de qualidade, o destino turístico tem que ter ações para que consolide a sua visitação. Este é o ponto mais importante na gestão do destino. Criar e consolidar esta demanda turística.

\subsubsection{Incorporação Imobiliária em destinos turísticos}

Uma das formas de aumentar a oferta de hospitalidade, não sendo a tradicional da hotelaria, é a incorporação imobiliária, o que Silva e Umbelino (2017) denominaram de turismo residencial e que o autor desta pesquisa denomina de turismo imobiliário. Este tipo de turismo fez parte do Plano Estratégico Nacional de Turismo de Portugal com o objetivo de incrementar a oferta de residências para o uso turístico. Turismo residencial ou turismo imobiliário é a aquisição de um imóvel de 2a a. residência onde o adquirente não o utilize como sendo a principal moradia e que o mesmo encontre-se em local turístico, para ser considerado como tal, algumas premissas são exigidas: i) o turista desloca para o local fora do seu habitual; ii) o turista viaja do seu local residencial para um destino e que não fique um longo tempo; iii) o turista pernoita pelo menos 1 noite; iv) o turista tem uma estada inferior a 12 meses consecutivos e v) o motivo principal não seja a trabalho e sim lazer e férias (Silva e Umbelino, 2017).

No Brasil esta modalidade surgiu com os modelos de condo-hotéis como forma, de um lado, de investimento imobiliário para os compradores dos imóveis e de outro lado, como forma de aumentar a oferta de disponibilidade de hospitalidade, seja para lazer, em locais turísticos ou para negócios em grandes centros urbanos.

Este modelo de negócio foi muito importante na década de 1990 onde grandes incorporadores imobiliários associaram-se com grandes cadeias hoteleiras e construíram uma quantidade significativa de empreendimentos residenciais com serviços hoteleiros, os denominados condo-hotéis. A cadeia do negócio do condo-hotel compõe-se: do incorporador imobiliário, o responsável pelas vendas dos imóveis, pela construção e entrega aos compradores; dos compradores dos imóveis que buscam a sua 2a. residência para férias ou buscam alternativas de investimentos; dos gestores hoteleiros, cadeias hoteleiras, que administram os hotéis, cobrando taxas de administração, remunerando os investidores dos imóveis, bem como, oferendo serviços hoteleiros aos clientes de hospitalidade nos destinos turísticos.

Portanto, este sistema diferencia do sistema da hotelaria tradicional, onde na hotelaria tradicional tem um investidor ou investidores de um único imóvel que é composto de um empreendimento com vários quartos hoteleiros, ou seja, no direito imobiliário entende-se com uma única matrícula de um único imóvel. Já a incorporação imobiliária ela sofre uma alteração substancial na sua composição jurídica, no terreno são construídos não quartos de hotéis e sim imóveis independentes com matrículas independentes, portanto, cada 
imóvel deste tem um proprietário que se juntam em um condomínio edilício para a gestão do empreendimento. Geralmente o síndico deste condomínio é a gestora hoteleira.

No Brasil a incorporação imobiliária e a gestão condominial estão disponibilizadas na lei de Incorporação Imobiliária 4.591 de 16 de dezembro de 1964 (Farias, 2015).

\subsubsection{Hotelaria Turística}

A indústria hoteleira no Brasil, diferentemente de outros países desenvolvidos, é dominada por pequenos hotéis, ao contrário, de grandes cadeias hoteleiras que dominam as economias desenvolvidas. A incorporação imobiliária facilitou o aumento da oferta da disponibilidade hoteleira no Brasil em função da necessidade de investimentos altos em construir hotéis na forma tradicional. Portanto, os empreendedores hoteleiros viram na incorporação imobiliária uma alternativa de crescer a oferta de unidades hoteleiras. No Brasil alguns casos cresceram desta forma, principalmente na região Centro Oeste, mais precisamente na região das Águas Quentes.

Nos hotéis tradicionais o maior desafio tem sido ter uma ocupação boa durante todo o ano. O turismo brasileiro é muito sazonal dependente do seu destino, e é muito dependente dos dois períodos de férias escolares, janeiro e julho. Verão e inverno determinam os destinos mais procurados, praias no verão e montanhas e águas quentes no inverno. Como a estrutura da indústria hoteleira, como foi dito acima, é dominada por pequenos hotéis há uma dificuldade muito grande em ter uma ocupação que possibilite uma rentabilidade satisfatória no negócio.

Uma alternativa encontrada pela indústria hoteleira para otimizar a sua taxa de ocupação foi o time sharing. Importada da Europa, do México e dos Estados Unidos a venda de time sharing no Brasil iniciou-se, profissionalmente, em 1999, com o Rio Quente Resorts, o autor deste artigo foi responsável pela implantação e implementação do projeto, que hoje é o maior do Brasil. A venda de time sharing na hotelaria tradicional consiste em vender diárias antecipadas por um determinado período do tempo. Para o hoteleiro é importante o fator de aumento na taxa de ocupação na medida que está vendendo diárias antecipadas, para o cliente, ele garante as férias para os próximos anos com a família a um preço com desconto bem vantajoso.

Portanto, o time sharing é uma alternativa de aumentar a taxa de ocupação dos hotéis tradicionais, esta modalidade é mais encontrada nos resorts e hotéis de lazer em destinos turísticos. Segundo Neto e Cunha (2017), o produto time sharing é um direito de uso que o cliente tem um prazo limite para a sua utilização.

Outra característica deste produto oferecido pela hotelaria e muito importante para o cliente é a possibilidade de utilizar uma rede nacional ou internacional de intercâmbio, ou seja, em determinado período ele pode escolher, dentre as alternativas, outros destinos turísticos, trocando o período que ele tem direito com outro destino.

\subsubsection{Multipropriedade Imobiliária}

Outra alternativa de aumentar a oferta da hospitalidade, além, é claro, da hotelaria tradicional e da incorporação imobiliária tradicional, é a alternativa do fractional, agora rebatizada no Brasil de multipropriedade. Esta modalidade de aumento da oferta de unidades com serviços hoteleiros tem sido extremamente importante, pois, com esta alternativa os destinos turísticos atingem maiores volumes em relação a este aumento de oferta de unidades hoteleiras quando comparados com a hotelaria e incorporação tradicionais

A razão para este ganho é simples, esta modalidade, a multipropriedade, atinge um público relativamente maior do que o público investidor da incorporação tradicional, pois os valores de investimentos são divididos entre os proprietários da unidade imobiliária turística (Camozzi e Pereira, 2017). 
Este cálculo do potencial de compra deu-se pela renda média familiar dos visitantes no destino turístico. As faixas de renda familiar compreendida nesta pesquisa é de que $15 \%$ dos turistas ganham mais do que $R \$ 12$ mil por mês, enquanto, $65 \%$ deles ganham entre R\$ 6 a R\$ 12 mil por mês. Enquanto apenas os turistas que ganham $\mathrm{R} \$ 12$ mil por mês conseguem adquirir uma unidade imobiliária turística com pagamentos mensais em torno de $\mathrm{R} \$ 1,5$ mil mês, os turistas que ganham na faixa intermediária entre $\mathrm{R} \$ 6$ mil e $\mathrm{R} \$ 12$ mil conseguem adquirir parte do imóvel, através da multipropriedade, pagando em torno de R\$ 400 a $\mathrm{R} \$ 600$ por mês, conforme pesquisa, abaixo, realizada em Caldas Novas, tabela 1.

O produto de multipropriedade dá acesso aos clientes que não conseguiriam adquirir sozinhos estas unidades imobiliárias turísticas nos destinos turísticos que gostariam de ter a sua 2ª. residência. Isso só é possível desde que os multiproprietários aceitam dividir o uso da propriedade com outros, estabelecendo uma tabela de uso por semanas durante um ano, exemplo: uma unidade que é vendida para 13 multiproprietários dará direito a cada um a 4 semanas de uso por ano. Em contrapartida, os valores dos investimentos, os custos de manutenção, as taxas de propriedade e a limpeza da unidade são divididas também entre os proprietários.

A pesquisa apresentada na tabela 1 abaixo norteou os investimentos de multipropriedade no território Brasileiro, hoje já são mais de 14 destinos turísticos: Caldas Novas (GO); Olímpia (SP), Porto Seguro (BA); Gramado (RS); Pedra Azul (ES); Penha (SC), Florianópolis (SC); Suzano (SP); Rio de Janeiro (RJ), Buzios (RJ); Pipa (RN); Campos de Jordão (SP); Bento Gonçalves (RS) e São Pedro (SP), até o final do ano de 2019, a multipropriedade será lançada em: Fortaleza (CE); Terezópolis (RJ); Porto de Galinha (PE); Londrina (PR) e Itaparica (BA).

\subsection{Pesquisa Caldas Novas (GO)}

Conforme HMS (2008), demonstrou-se a quantidade percentual dos clientes visitantes da cidade que poderia adquirir o produto de multipropriedade. A pesquisa constatou que uma grande parte dos turistas poderia adquirir um produto que fosse mais barato, porém, que pudesse ser compartilhado com outros compradores, dividindo o valor do investimento e o valor dos custos mensais da propriedade de lazer. Esse produto compartilhado, com valor de investimento menor, daria acesso a um maior número de pessoas para aquisição da 2a. moradia.

No quadro abaixo resume-se os resultados da pesquisa focando a renda familiar dos entrevistados.

Tabela 1

\begin{tabular}{|c|c|c|}
\hline Valores em R\$ mil & Quantidade & $\%$ \\
\hline Abaixo de 5 & 277 & $26,6 \%$ \\
\hline Entre 5 e 6 & 108 & $10,4 \%$ \\
\hline Entre 6 e7 & 54 & $5,2 \%$ \\
\hline Entre 7 e 8 & 32 & $3,1 \%$ \\
\hline Entre 8 e 9 & 77 & $7,4 \%$ \\
\hline Entre 9 e 10 & 14 & $1,3 \%$ \\
\hline Entre 10 e 11 & 89 & $8,5 \%$ \\
\hline Entre 11 e 12 & 5 & $0,5 \%$ \\
\hline Acima de $12 \mathrm{mil}$ & 123 & $11,8 \%$ \\
\hline Não respondeu & 262 & $25,2 \%$ \\
\hline Total & 1.041 & $100,0 \%$ \\
\hline
\end{tabular}

Os resultados da pesquisa, conforme quadro acima, foi a qualificação de 123 turistas (famílias), entende-se como qualificação clientes com potencial econômico de renda em condições de compra do imóvel, que tinham como renda requerida acima de $\mathrm{R} \$ 12$ mil mensais, correspondente a $11,8 \%$ do total pesquisado. $A$ renda requerida 
partiu da premissa de que para a aquisição do referido imóvel o cliente não poderia destinar mais do que $15 \%$ da sua renda mensal, ou seja, $\mathrm{R} \$ 1.800$ durante os 48 meses do prazo de pagamento da compra do imóvel.

$\mathrm{Na}$ análise do quadro acima, referente às pesquisas, chama a atenção ao número pequeno de potenciais compradores do imóvel aliado a uma grande oferta de empreendimentos à venda na cidade, portanto, tendo como base nesta premissa de renda, concluiu-se que havia no mercado de Caldas Novas uma oferta de empreendimentos maior do que a demanda por eles, ocasionando, o que foi constatado, uma velocidade menor nas vendas.

Por outro lado, o quadro acima remete a outra análise, uma oportunidade de negócio, considerando que entre as faixas de renda de $\mathrm{R} \$ 5$ mil a $\mathrm{R} \$ 12$ mil mensais foram pesquisados 379 clientes que correspondem a 36,41\%, que somados com os que ganham acima de $\mathrm{R} \$ 12 \mathrm{mil}$, chega-se a um percentual de quase $50 \%$ dos clientes pesquisados e de $65 \%$ dos que responderam à pergunta sobre renda, este extrato de público passa a ser significativamente maior para aquisição de um produto que tenha preço inferior e que possa ser substituto ao produto imobiliário originariamente ofertado.

Oportunizando a análise, somente na premissa de renda, pode-se deduzir que se fosse desenvolvido um produto substituto ao produto original, teria uma demanda potencial maior do que existe hoje para o produto original.

Inicialmente cabia discutir o que leva uma família adquirir um imóvel na cidade de Caldas Novas. Por ser uma cidade turística, descartou-se a possibilidade de aquisição ser para uma primeira moradia, ou uma primeira residência. Ficou-se então com a possibilidade de uma segunda residência, um apartamento de veraneio. Portanto, os principais apelos para aquisição são: curtir férias, folgas e descansos com a família em alguns períodos do ano. Por outro lado, a aquisição de um imóvel, traz um aspecto de status, além de ser uma propriedade imobiliária que eleva o patrimônio líquido da família. No caso de Caldas Novas, além do lazer e da propriedade familiar, tem-se ainda a questão de possíveis rendimentos financeiros quando do não uso do apartamento pela família, o mesmo podendo ser alugado para outras pessoas nos períodos que a família tem direito ao uso.

Portanto, o desafio era encontrar um produto substituto que poderia oferecer tudo isso ao cliente por um preço menor, onde o objetivo era aumentar a demanda potencial do produto.

No mercado mundial o negócio se desenvolve com as grandes mansões de lazer e apartamentos em destinos turísticos, uma venda diferente da venda tradicional. Esta venda consiste em dividir a unidade imobiliária em frações da mesma e vender cada fração para pessoas distintas. Com isso há um compartilhamento entre estas pessoas, do preço de venda, do custo de manutenção e principalmente do uso do imóvel. O nome deste produto no mercado é fractional, rebatizado no Brasil como multipropriedade.

\section{Resultados}

A análise dos resultados permite demonstrar a contribuição da implantação da multipropriedade para o destino turístico de Olímpia. O crescimento da variável dependente, oferta de unidades hoteleiras, gerou crescimento simultâneo nas variáveis independentes: o número de clientes hospedados; o número de clientes consolidados nos parques aquáticos e a arrecadação do munícipio. Como o hotel Olímpia Park Resorts, no formato de multipropriedade, foi inaugurado em duas etapas, a primeira etapa inaugurada em julho de 2018 com 456 unidades hoteleiras e a segunda etapa inaugurada em novembro de 2019 com mais 456 unidades hoteleiras, a base comparativa é ainda restrita em função da ocorrência da pandemia Covid-19 durante a pesquisa, foi necessário excluir os meses afetados pela pandemia para não prejudicar os resultados. Os dados dos resultados abaixo demonstram a tendência desta contribuição. Com base na inauguração do Hotel Olímpia Park Resort em multipropriedade, constata-se a sua ocupação pelos clientes, bem como, o aumento de visitantes nos dois 
parques aquáticos na cidade de Olímpia e por fim demonstra um aumento na receita de impostos, taxas e contribuições auferida pela prefeitura da cidade como consequência de uma valor de renda ocorrida no período.

\subsection{Hotel Olímpia Park Resort}

Em julho de 2018 foram inauguradas 2 torres das 4 previstas do Hotel Olímpia Park Resort, ofertando para a cidade 456 novas unidades habitacionais e em novembro de 2019 as duas torres restantes foram inauguradas completando assim 912 unidades com aproximadamente 4.560 leitos. Para efeito de comparação e análise dividimos, considerando os últimos dados disponíveis e também considerando o período que antecede o início da pandemia do Covid-19 que afetou sobremaneira o setor de turismo, em dois períodos que contemplam a oferta das 912 unidades habitacionais. A análise foi realizada comparando o período de dezembro de 2018 a fevereiro de 2019 com o período de dezembro de 2019 a fevereiro de 2020. O limite do período de análise como explicado anteriormente deve-se ao fato de a 2a. etapa do hotel ter sido entregue em novembro de 2018, portanto, o início da operação com 100\% do hotel entregue foi o mes de dezembro 2018 e do último mes realizado sem o efeito da pandemia do Covid-19 que foi o mes de fevereiro de 2020.

Em princípio a análise pode ser comprometida em função do pouco tempo, porém, esta é a ressalva dos resultados abaixo, o acompanhamento maior deverá ser realizado após os efeitos da pandemia, porém, com toda a certeza os dados apresentados abaixo demonstram uma tendência significativa da alavancagem do turismo em função da implantação do sistema de multipropriedade na cidade de Olímpia.

A tabela 2 apresenta uma evolução no número de clientes representativa saindo de 22 mil clientes para 47 mil clientes no período que se encerra em fevereiro de 2020 , crescimento de $112 \%$ em relação ao mesmo período do ano anterior.

Tabela 2

Número de clientes hospedados no Hotel Olímpia Park Reso

\begin{tabular}{|c|c|c|c|c|}
\hline & \multicolumn{2}{|c|}{$\begin{array}{c}\text { Trimestre Dezembro/2018 e 2019, } \\
\text { Janeiro e Fevereiro 2019/2020 }\end{array}$} & \multicolumn{2}{|c|}{ Variação } \\
\hline & $2019 / 2020$ & $2018 / 2019$ & Pax & $\%$ \\
\hline Dezembro & 16.262 & 8.765 & 7.497 & $85,5 \%$ \\
\hline Janeiro & 18.168 & 7.796 & 10.372 & $133,0 \%$ \\
\hline Fevereiro & 12.733 & 5.706 & 7.027 & $123,2 \%$ \\
\hline Total & 47.163 & 22.267 & 24.896 & $111,8 \%$ \\
\hline
\end{tabular}

\subsection{Frequência nos parques aquáticos}

Outro resultado apurado no artigo é o crescimento no número de clientes nos parques aquáticos da cidade de Olímpia, do parque aquático tradicional Thermas dos Laranjais, um dos maiores do mundo e do recente inaugurado parque aquático Hot Beach.

A tabela 2 apresenta um crescimento no número de clientes hospedados no Hotel Olímpia Park Resort de 24.896 nos períodos analisados, enquanto as tabelas 3, 4 e 5 apresentam crescimento no número de visitantes nos parques aquáticos da cidade. A relação causa e efeito do maior número de clientes no hotel proporcionando maior número de clientes nos parques deve-se ao fato do destino turísitico de Olímpia ter como âncora principal o parque aquático Thermas dos Laranjais, foi onde tudo começou. O mesmo cliente que fica hospedado em média 3 dias frequenta tanto o Thermas dos Laranjais como o Hot Beach e pelas tabelas acima na proporção de $74 \%$ e $26 \%$. respectivamente. 
O crescimento no ano de 2019 dos dois parques aquáticos foi de aproximadamente $25 \%$ em relação ao ano de 2017, saindo de 2 milhões de visitantes por ano para 2,5 milhões, somando os dois parques de Olímpia, eles ficam em 2‥ lugar no ranking de parques aquáticos do mundo, sendo o 1‥ o Chinês Chimelong com 3 milhões de visitantes no ano. Pela tendência em dois anos os parques aquáticos de Olímpia atingem o 1‥ lugar do ranking mundial.

Tabela 3

Número de visitantes no Parque Aquático Thermas dos Laranjais

\begin{tabular}{lrrrrr}
\hline & \multicolumn{2}{c}{$\begin{array}{c}\text { Trimestre Dezembro/2018 e 2019, } \\
\text { Janeiro e Fevereiro 2019/2020 }\end{array}$} & & \multicolumn{2}{c}{ Variação } \\
\cline { 2 - 3 } \cline { 5 - 6 } & $2019 / 2020$ & $2018 / 2019$ & & Visitantes & $\%$ \\
\hline Dezembro & 186.091 & 172.012 & & 14.079 & $8,2 \%$ \\
Janeiro & 276.698 & 243.306 & & 33.392 & $13,7 \%$ \\
Fevereiro & 117.952 & 88.941 & & 29.011 & $32,6 \%$ \\
\hline Total & 580.741 & 504.259 & & 76.482 & $15,2 \%$ \\
\hline
\end{tabular}

Fonte: Controladoria Hotel Olímpia Park Resort (2020)

Tabela 4

Número de visitantes no Parque Aquático Hot Beach

\begin{tabular}{lrrrrr}
\hline & \multicolumn{2}{c}{$\begin{array}{c}\text { Trimestre Dezembro/2018 e 2019, } \\
\text { Janeiro e Fevereiro 2019/2020 }\end{array}$} & & \multicolumn{2}{c}{ Variação } \\
\cline { 2 - 3 } \cline { 5 - 6 } & $2019 / 2020$ & $2018 / 2019$ & & Visitantes & $\%$ \\
\hline Dezembro & 71.302 & 70.576 & & 726 & $1,0 \%$ \\
Janeiro & 88.779 & 81.245 & & 7.534 & $9,3 \%$ \\
Fevereiro & 39.503 & 31.021 & & 8.482 & $27,3 \%$ \\
\hline Total & 199.584 & 182.842 & & 16.742 & $9,2 \%$ \\
\hline
\end{tabular}

Fonte: Controladoria Hotel Olímpia Park Resort (2020)

Tabela 5

Número de visitantes consolidado nos parques Thermas dos Laranjais e Hot Beach

\begin{tabular}{lrrrrrr}
\hline & \multicolumn{2}{c}{$\begin{array}{c}\text { Trimestre Dezembro/2018 e 2019, } \\
\text { Janeiro e Fevereiro 2019/2020 }\end{array}$} & & \multicolumn{2}{c}{ Variação } \\
\cline { 2 - 3 } \cline { 6 - 7 } & $2019 / 2020$ & $2018 / 2019$ & & Visitantes & $\%$ \\
\hline Dezembro & 257.393 & 242.588 & & 14.805 & $6,1 \%$ \\
Janeiro & 365.477 & 324.551 & & 40.926 & $12,6 \%$ \\
Fevereiro & 157.455 & 119.962 & & 37.493 & $31,3 \%$ \\
\hline Total & 780.325 & 687.101 & & 93.224 & $13,6 \%$ \\
\hline
\end{tabular}

Fonte: Controladoria Hotel Olímpia Park Resort (2020)

\subsection{Receita de impostos, taxas e contribuições da prefeitura da cidade de Olímpia}

Por último foi pesquisado a evolução da receita de impostos da prefeitura da cidade de Olímpia como forma de ratificar o crescimento significativo no número de visitantes na cidade, tanto no hotel como nos parques. Foi necessário apenas um ajuste no período de tempo analisado, como os impostos são recolhidos no mes seguinte ao período de apuração, foi considerado os meses de janeiro, fevereiro e março, que representam a apuração de dezembro, janeiro e fevereiro. 
Tabela 6

Receita de impostos, taxas e contribuições da prefeitura da cidade de Olímpia

\begin{tabular}{lrrrrr}
\hline & \multicolumn{2}{c}{ Anos } & & \multicolumn{2}{c}{ Variação } \\
\cline { 2 - 3 } \cline { 2 - 3 } & \multicolumn{1}{c}{2020} & 2019 & & Visitantes & \multicolumn{1}{c}{$\%$} \\
\hline Janeiro & 3.463 .945 & 3.379 .536 & & 84.409 & $2,5 \%$ \\
Fevereiro & 5.073 .784 & 4.162 .448 & & 911.336 & $21,9 \%$ \\
Março & 10.362 .069 & 8.628 .751 & & 1.733 .318 & $20,1 \%$ \\
\hline Total & 18.899 .798 & 16.170 .735 & & 2.729 .063 & $16,9 \%$ \\
\hline
\end{tabular}

Fonte: www.olimpia.sp.gov.br/portal/transparencia

Constata-se na tabela 6 crescimento da ordem de $17 \%$ na receita de impostos, taxas e contribuições da cidade de Olímpia o que indica que houve um fomento nas atividades produtivas da cidade. Considerando que a inflação no período analisado foi de 3,7\% (IPCA/IBGE), constata-se um crescimento real (acima da inflação) na receita de impostos da ordem de $12,7 \%$.

\section{Conclusões}

Para chegar-se nos resultados foi necessário uma extratificação no período de análise, sendo dezembro de 2019 a fevereiro de 2020 comparando com o mesmo período dos anos anteriores. Os períodos comparados foram os perídos anteriores a pandemia do Covid-19 para que não houvesse distorções no resultado. 0 acompanhamento dos resultados devem ser continuado para que se tenha um período maior de tempo de análise. Entretanto, os resultados apurados, mesmo em um período considerado curto, norteia a tendência da economia compartilhada aplicada no turismo.

A implantação do modelo de multipropriedade no segmento do turismo alavanca os negócios do destino turístico, pois abrange uma quantidade de cliente muito maior do que no modelo de incorporação tradicional. E os resultados comprovaram isso. Com a oferta das unidades de multipropriedade do Hotel Olímpia Park Resort aumentou-se o número de clientes comparativamente ao mesmo período do ano anterior em $112 \%$, foram quase 25 mil clientes adicionais hospedados no hotel. Por consequência os parques aquáticos da cidade de Olímpia receberam um público maior em 93 mil clientes, $14 \%$ a mais do que o mesmo período do ano anterior. Este dado sinaliza que os clientes frequentaram o parque mais do que 1 dia. E para comprovar os resultados a receita do municipio cresceu no período quase $17 \%$ em relação ao mesmo período do ano anterior, o ciclo: mais clientes no hotel, mais clientes no parque e mais receita para o destino turístico.

Portanto, a implantação do sistema de multipropriedade nos destinos turísticos no Brasil deve continuar, pois está comprovado que alavanca os negócios do turismo em função de atingir um número de clientes bem maior do que no modelo tradicional. O produto multipropriedade além de oferecer as férias para as famílias, oferece também a oportunidade, ou o acesso, ao bem físico que é o apartamento da 2a . casa da familia.

A WAM está presente em várias regiões turísticas do Brasil, dentre os quais, Caldas Novas (GO); Campos de Jordão (SP); São Pedro (SP); Suzano (SP); Pedra Azul (ES); Forianópolis (SC); Rio de Janeiro (RJ); Búzios (RJ); Gramado (RS); Bento Gonçalves (RS); Canela (RS); Porto Seguro (BA), além de Olímpia (SP) que foi o tema desenvolvido no artigo.

Em todos estes destinos turísticos será possível uma pesquisa semelhante a realizada em Olímpia para depois obter um modelo conceitual da implantação da multipropriedade no turismo brasileiro. 


\section{Referências bibliográficas}

Botsman, R., e Rogers, R. (2011). O que é meu é seu. Como o consumo colaborativo vai mudar o nosso mundo. Porto Alegre: Bookman.

Camozzi, C., e Pereira, M. (2017). Os cinco pilares absolutamente essenciais para o sucesso de um empreendimento fracionado. Férias Compartilhadas. A experiência do timeshare e da multipropriedade no Brasil. Maceió: Viva Editora, p. 91-102.

Castells, M. (2016). Sociedade em rede. São Paulo: Paz e Terra.

Chase, R. (2015). Economia Compartilhada. São Paulo: HSM do Brasil.

Farias, L. (2015). Teoria e Prática no direito imobiliário. São Paulo: Anhanguera Editoria Jurídica.

Gansky, L. (2011). Mesh. Rio de Janeiro: Alta Books Editoria.

HMS. (2008). Estudo inicial fractional/multipropriedade. Recuperado de : Estudo inicicial fractional/multipropriedade 2008 - WAM Comercialização (wamcomercializacao.com)

Lage, B. H. G., e Milone, P.C. (2000). Turismo teoria e prática. São Paulo: Editora Atlas.

Lima, F. (2017). Vacation Club como ferramenta essencial para a sustentabilidade da hotelaria de lazer. Férias Compartilhadas. A experiência do timeshare e da multipropriedade no Brasil. Maceió: Viva Editora.

Kother, P. (2015). Capitalismo em Confronto. Rio de Janeiro: Best Business.

Meirelles, R. (2014). O consumo da classe C no Brasil. Palestra proferida CONAC WAM. Caldas Novas, Goiás. Recuperado de: https://youtu.be/LMhgosE6dVc

Neto, F. C.; e Cunha, A. L. (2017). Investir em modelos de Vacation Ownership: multipropriedade ou tempo compartilhado. Férias Compartilhadas. A a experiência do timeshare e da multipropriedade no Brasil. Maceió: Viva Editora.

Parker, G. G., Alstyne, M .W. V., e Choudary, S.P. (2016). Plataforma. A revolução da estratégia. São Paulo: HSM do Brasil.

Pereira, I., Veloso, F., e Bingwen, Z. (2013). Armadilha da renda média. Visões do Brasil e da China. Rio de Janeiro: FGV Editora.

Petrochhi, M. (2001). Gestão de Polos Turísticos. São Paulo: Futura.

Picketty, T. (2014). O capital no século XXI. São Paulo: Intrínseca.

Rifkin, J. (2001). A era do acesso. A transição de mercados convencionais para networks e o nascimento de uma nova economia. São Paulo: Makron Books.

Rifkin, J. (2016). Sociedade com custo marginal zero. São Paulo: M. Books.

Silva, F., e Umbelino, J. (2017). Planejamento e desenvolvimento turístico. Lisboa: Lidel.

Stone, B. (2017). As upstarts. Como a Uber, o Airbnb e as killer companies do novo Vale do Silício estão mudando o mundo. Rio de Janeiro: Intrínseca.

Timms, H., e Heimans, J. (2018). O novo poder. Como disseminar ideias, engajar pessoas e estar sempre um passo à frente em um mundo hiperconectado. Rio de Janeiro: Intrínseca.

Viagens Cinematográficas (2018). Portal Destinos do Brasil. Recuperado de:

https://viagenscinematograficas.com.br/2018/12/melhores-destinos-do-brasil-top-10.html

Esta obra está bajo una Licencia Creative Commons

Attribución-NoCommercial 4.0 International

(c) B BY-NC 